\title{
ÍNDICE DE AUTORES
}

Galaxis Borja González (Ecuador). Realizó sus estudios de Historia y Antropología en la Universidad de Hamburgo. Es profesora agregada del Área de Historia de la Universidad Andina Simón Bolívar, Sede Ecuador (UASB-E), donde coordina la Maestría en Historia y anteriormente lo hizo con la Especialización en Historia del Arte. También ha sido docente en la Universidad de Kassel (Alemania) y el Departamento de Historia de la Pontificia Universidad Católica del Ecuador. Es autora de publicaciones especializadas sobre las relaciones de intercambio cultural entre América y Europa; la influencia de los impresos jesuíticos en la construcción de los imaginarios europeos sobre América del Sur; las sociabilidades republicanas, retóricas liberales y sujetos artesanos en Ecuador de mediados del siglo XIX, desde una perspectiva transnacional y de historia cruzadas.

Carmen Fernández-Salvador (Ecuador). Historiadora del arte, obtuvo su $\mathrm{PhD}$ en la Universidad de Chicago (2005). Actualmente es profesora y decana del Colegio de Ciencias Sociales y Humanidades en la Universidad San Francisco de Quito. Durante el semestre de otoño de 2015 fue Robert F. Kennedy Visiting Professor en el Departamento de Historia del Arte y Arquitectura de la Universidad de Harvard. Ha publicado varios estudios sobre arte colonial e historiografía, entre los que destacan "Historia del Arte Colonial Quiteño: un aporte historiográfiCo", en Arte colonial quiteño: renovado enfoque y nuevos actores (2007) y Encuentros y desencuentros con la frontera imperial: la iglesia de la Compañía de Jesús de Quito y la misión en el Amazonas (siglo XVII) (2018).

Fernando Garcés V. (Ecuador). Doctor en Estudios Culturales Latinoamericanos (Universidad Andina Simón Bolívar, Sede Ecuador), maestro en Ciencias Sociales (FLACSO Ecuador) y licenciado en Ciencias de la Educación (Universidad de Cuenca). Actualmente es docente de la Universidad Politécnica Salesiana, sede Quito, y ha sido profesor de pregrado y posgrado en varias universidades de Ecuador y Bolivia. Trabajó como investigador del Instituto de Investigaciones Antropológicas y Museo de la Universidad Mayor de San Simón, Cochabamba, 
Bolivia, entre 2010 y 2017. Ha publicado libros y artículos en revistas nacionales y extranjeras sobre temas de interculturalidad, lengua y conocimiento del quechua/quichua, semiótica andina, plurinacionalidad, autonomías y territorios indígenas y derechos de pueblos indígenas.

William Alfonso López Rosas (Colombia). Profesor del Instituto de Investigaciones Estéticas de la Universidad Nacional de Colombia (UNC). Doctor en Arte y Arquitectura por esa misma institución. En los años noventa coordinó los grupos de mediadores pedagógicos del Museo de Arte del Banco de la República de Colombia y el Museo Nacional de Colombia. Fue director del Museo de Arte de la UNC, donde lideró el grupo gestor de la Maestría en Museología y Gestión del Patrimonio, que actualmente coordina. Es cofundador del grupo de investigación Taller Historia Crítica del Arte y del grupo de investigación Museología Crítica y Estudios del Patrimonio Cultural; así como miembro de la Red Conceptualismos del Sur. Autor de artículos y textos sobre historia del arte en Colombia y los museos de ese país. Se desempeña como director y realizador del programa radial Museos en contexto en la emisora de la UNC.

Trinidad Pérez Arias (Ecuador). Historiadora del arte con doctorado en Estudios Culturales Latinoamericanos en la UASB-E, donde es profesora agregada, investigadora y coordinadora de la Especialización Superior en Museos y Patrimonio Histórico. Sus investigaciones se han centrado en el surgimiento del arte moderno en las primeras décadas del siglo XX en el contexto de la estructuración social del campo moderno del arte en el Ecuador y en su relación con representaciones indigenistas en la pintura. 